\title{
INVESTIGATION OF THE RESPONSE VARIABILITY OF BASE-A ISOLATED BUILDING EQUIPPED WITH LEAD RUBBER BEARINGS
}

\author{
MARCO FURINGHETTI ${ }^{1,2}$, AND ALBERTO PAVESE ${ }^{1}$ \\ ${ }^{1}$ University of Pavia \\ Via Ferrata 3, 27100 Pavia (Italy) \\ a.pavese@unipv.it \\ marco.furinghetti@unipv.it \\ ${ }^{2}$ EUCENTRE \\ via Ferrata 1, 27100 Pavia (Italy)
}

Key words: Property modification factors, Flat sliders, Lead Rubber bearing isolators, Parametric study, Base Isolation.

\begin{abstract}
Nowadays analytical models of seismic isolators can fairly reproduce the force response of such devices, when implemented in a large variety of structural systems, such as buildings and bridges. Consequently, realistic hysteretic rules are available for the definition of the dynamic system for Non-Linear Time History Analyses, and earthquake simulations of the considered isolated structural systems can be computed. Such models are generally defined, according to mean values of mechanical properties of isolation devices, even though a certain variability has been experimentally assessed: precisely, statistical analyses of the outcomes of test database have outlined that the main response parameters of isolators should be considered as random variables, rather than as deterministic values. On the other hand, in the common practice both design and assessment procedures are mainly based on deterministic approaches, and bound analyses are ruled in just few standard codes.

The present endeavor presents a wide parametric study on a case study structure, in order to assess the variability of the main response parameters, by accounting for random mechanical properties of isolation devices. Precisely, a combination of Lead Rubber Bearings and Flat Slider devices have been considered, and the spatial layout of isolators has been defined, according to a given performance point. The structural response of the case study building has been computed through Non-Linear Time History Analyses, by extracting 10'000 individual values of mechanical properties of devices. Presented results are related to the mean response of a spectrum-compatible set of natural records, in terms of displacement and force of both superstructure and isolation system.
\end{abstract}




\section{INTRODUCTION}

The present research work provides results of a parametric study on a case study structure, base-isolated by means of a combination of Lead Rubber Bearings and Flat Sliders. The aim of the study was to highlight the main consequences of the effective experimental variability of the main mechanical properties of the adopted Lead Rubber Bearing devices on the overall seismic response of the building under investigation. The probability density functions for the most important mechanical properties have been defined through a statistical analysis of the outcomes of hundreds of dynamic tests performed at the Laboratory of EUCENTRE Foundation of Pavia (Italy - [9]), in agreement with the standard codes for anti-seismic devices ([2], [3]). The hysteretic response returned by all tests has been approximated by a bilinear constitutive law, in order to compute the rubber shear modulus and the lead core yielding strain and stress. Results are provided as mean response parameters, normalized with respect to the reference case, related to deterministic values of mechanical properties.

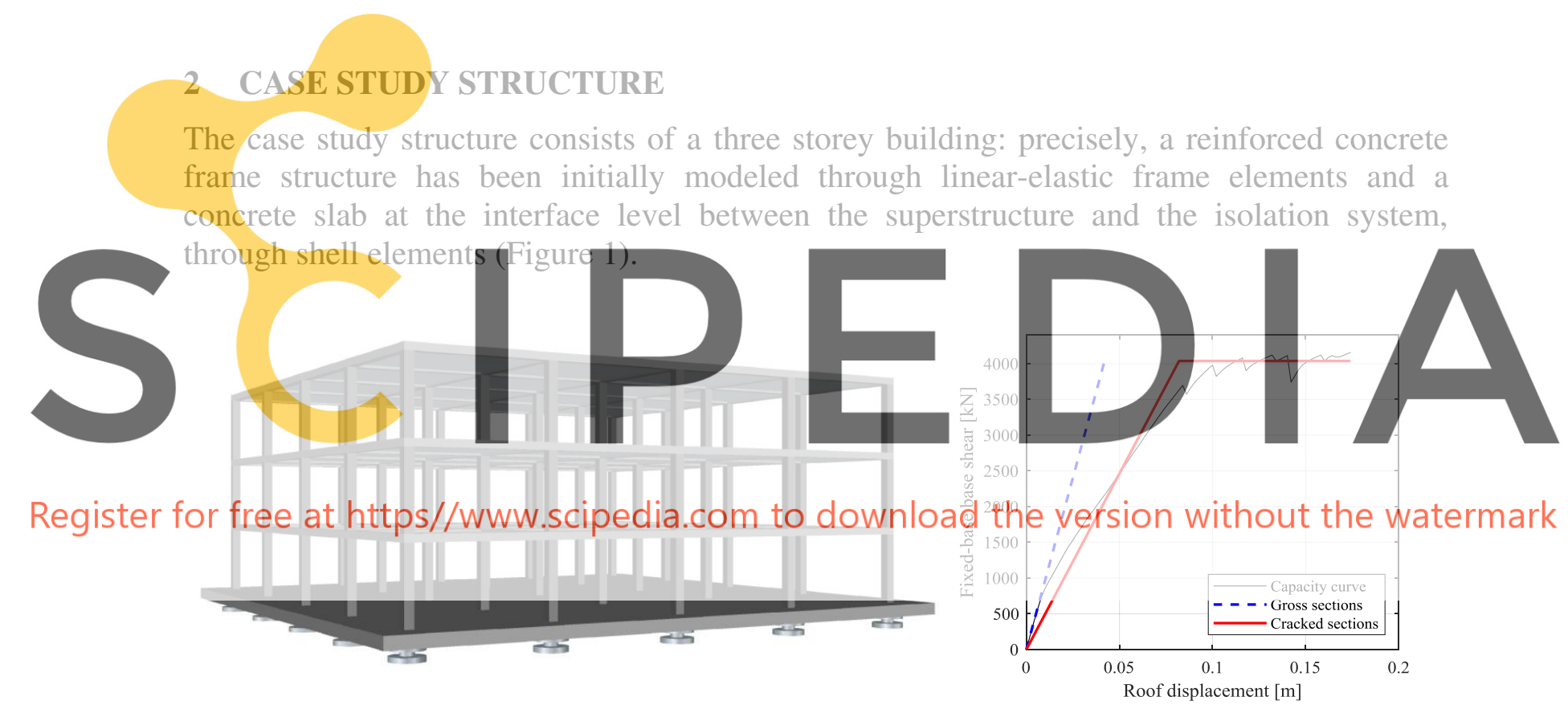

Figure 1: Case study structure.

Four spans along both $\mathrm{x}$ and $\mathrm{y}$ directions are designed, $6 \mathrm{~m}$ long, and an interstorey height of $3 \mathrm{~m}$ has been considered. At the ground level of the building, a reinforced concrete slab represents the interface between the building itself and the isolation system: the thickness is $500 \mathrm{~mm}$ and plan dimensions have been obtained by considering the plan development of the superstructure, increased by $1.5 \mathrm{~m}$ along all sides $(27 \mathrm{~m} \times 27 \mathrm{~m})$. Flexural stiffness coefficients have been reduced by means of scale factors (lower than 1), in order to fit the linear-elastic branch of the bi-linear approximation of the capacity curve. The non-linear capacity curve has been obtained through a pushover analysis carried out by using the software SeismoStruct [10], which allows to model force-based frame elements, with distributed plasticity and nonlinear constitutive laws for materials (Mander's model for Concrete and Menegotto-Pinto's 
model for reinforcement steel); moreover, in order to obtain the proper strength and ductility of the sections, confinement effects in the concrete core of columns has been modeled. Isolation devices are represented by a combination of Lead Rubber Bearings and Flat Sliders. Since a large number of analyses have to be performed, the overall system has been reduced to a Multi Degree of Freedom oscillator, by applying a static condensation procedure to the full 3D FEM model of the structure ([1], [6]).

The returned stiffness matrix is a full matrix, with non-null components: this result is a direct consequence of the adopted static condensation procedure, which allows to account for the actual flexural behavior in the out-of-plane direction for beams, together with torsional behavior of each floor. The force response of the isolation system has been separately implemented, by using a non-linear hysteretic constitutive law.

\section{MECHANICAL PROPERTIES OF ISOLATORS}

A combination of Lead Rubber Bearings ([8]) and Flat Sliders ([5]) has been adopted for the analyzed case study structure. Precisely, the isolation layout has been obtained by considering an effective period of $3.0 \mathrm{sec}$ and an equivalent viscous damping equal to $30 \%$; consequently, the isolation system is made up of 10 Lead Rubber Bearings and 15 Flat Sliders. The main characteristics of LRB devices are

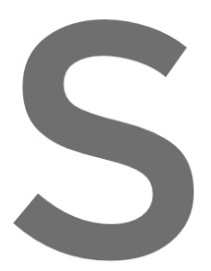

- Total height of LRB devices: 203mm;
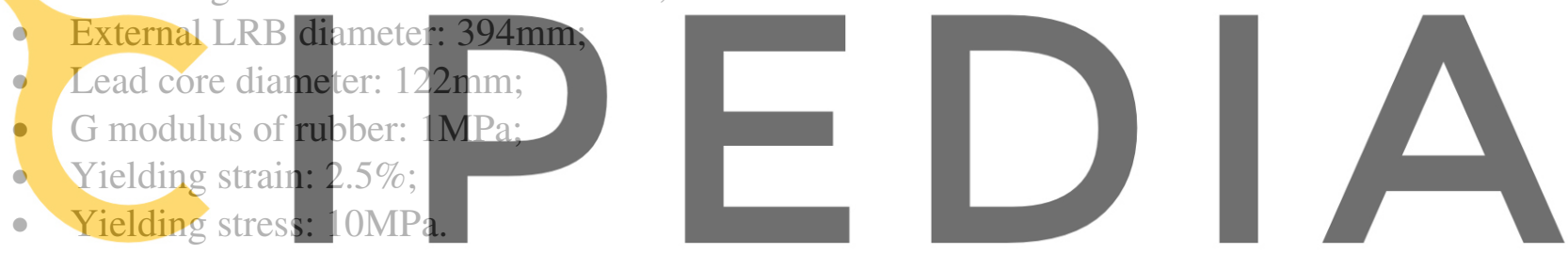

For LRB devices the main mechanical properties are represented by the shear modulus $G$ of

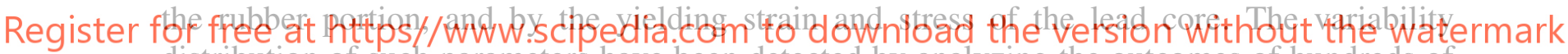
distribution of such parameters have been detected by analyzing the outcomes of hundreds of dynamic experimental tests performed at EUCENTRE Laboratory in Pavia (Italy) and results are provided in Figure 2 and Figure 3.

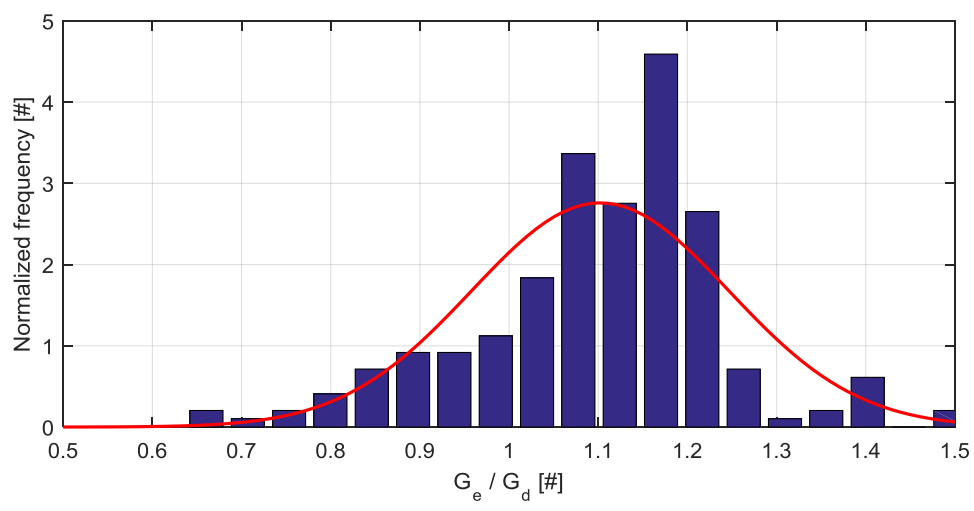

Figure 2: Distribution of the normalized Shear modulus of rubber. 

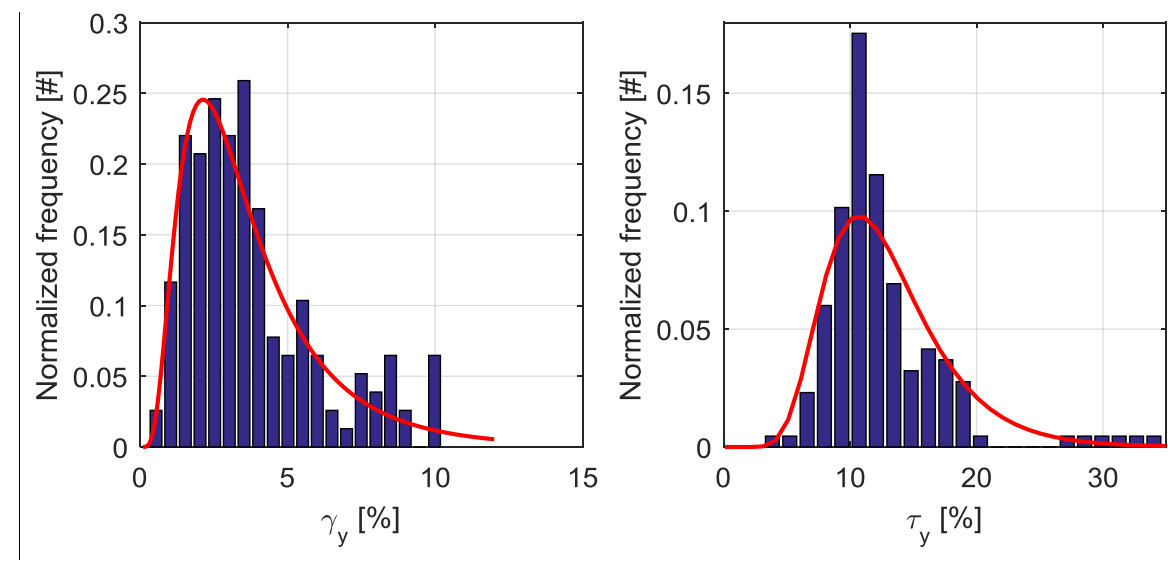

Figure 3: Distribution of the normalized yielding strain (left) and stress (right) of the lead core.

Precisely, a Gaussian distribution can be assumed for the shear modulus, with mean value equal to 1 and a coefficient of variation equal to $\pm 14 \%$; on the other hand, for both yielding strain and stress, lognormal distributions can be considered, with unitary mode and $106 \%$ and $63 \%$ standard deviation for yielding strain and stress respectively. Thus, for all the analyses of the present study, the numerical value of the ratio between the actual and the design mechanical property has been randomly extracted by a numerical simulator, according to the

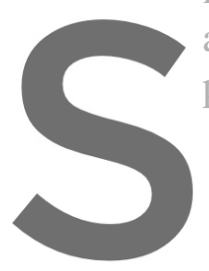
assumed probability density fun parameters of the overall system has been studied.

\section{DEFINITION OF'THE DYNAMIC SYSTEMI}
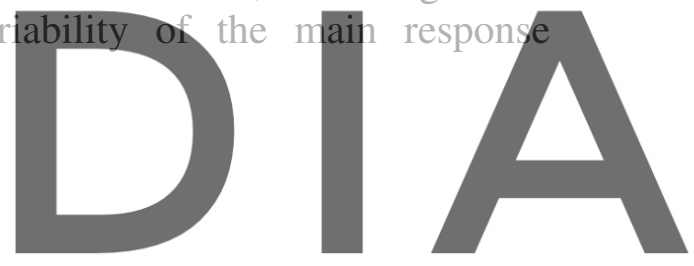

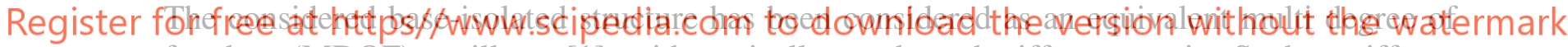
freedom (MDOF) oscillator [1], with statically condensed stiffness matrix. Such a stiffness matrix is able to reproduce the actual dynamic properties of the system, and approximately same results of a full time history analysis on a 3D FEM model can be obtained ([6]). Thus, the dynamic system can be expressed as follows:

$$
\overline{\bar{M}} \cdot\left(\begin{array}{l}
\ddot{u}_{0} \\
\ddot{u}_{1} \\
\ddot{u}_{2} \\
\ddot{u}_{3}
\end{array}\right)+\left(\begin{array}{l}
\frac{u_{0}}{u_{1}} \\
u_{2} \\
u_{3}
\end{array}\right)+\left\langle F_{i s}\right\rangle \cdot\left(\begin{array}{l}
\frac{1}{0} \\
0 \\
0
\end{array}\right)=-\overline{\bar{M}} \cdot\left(\begin{array}{c}
\underline{1} \\
1 \\
1 \\
1
\end{array}\right) \cdot \ddot{x}_{g}
$$

Being:

- $\overline{\bar{M}}$ the condensed mass matrix of the system;

- $\overline{\bar{K}}$ the condensed stiffness matrix of the system;

- $u_{i}$ the translational degrees of freedom at the centre of mass location of the $\mathrm{i}$-th floor;

- $\ddot{x}_{g}$ the considered ground acceleration time series; 
- $\left\langle F_{i s}\right\rangle$ the isolation force response.

No additional viscous damping matrix has been accounted for, since the non-linear hysteretic behavior of the isolation system already provides hysteretic damping, in order not to underestimate the structural response. The isolation system has been modeled as a single device, equivalent to the whole set of isolators, by means of the following equations:

$$
\left\langle F_{i s}\right\rangle=\left\langle F_{L R B}\right\rangle+\left\langle F_{F S}\right\rangle
$$

Being:

- $\left\langle F_{L R B}\right\rangle$ the force response of all the Lead Rubber Bearing devices;

- $\left\langle F_{F S}\right\rangle$ the force response of the implemented Flat Sliders;

The hysteretic parameters which allows to model the hysteretic response of both the isolation devices are shown in Figure 4.
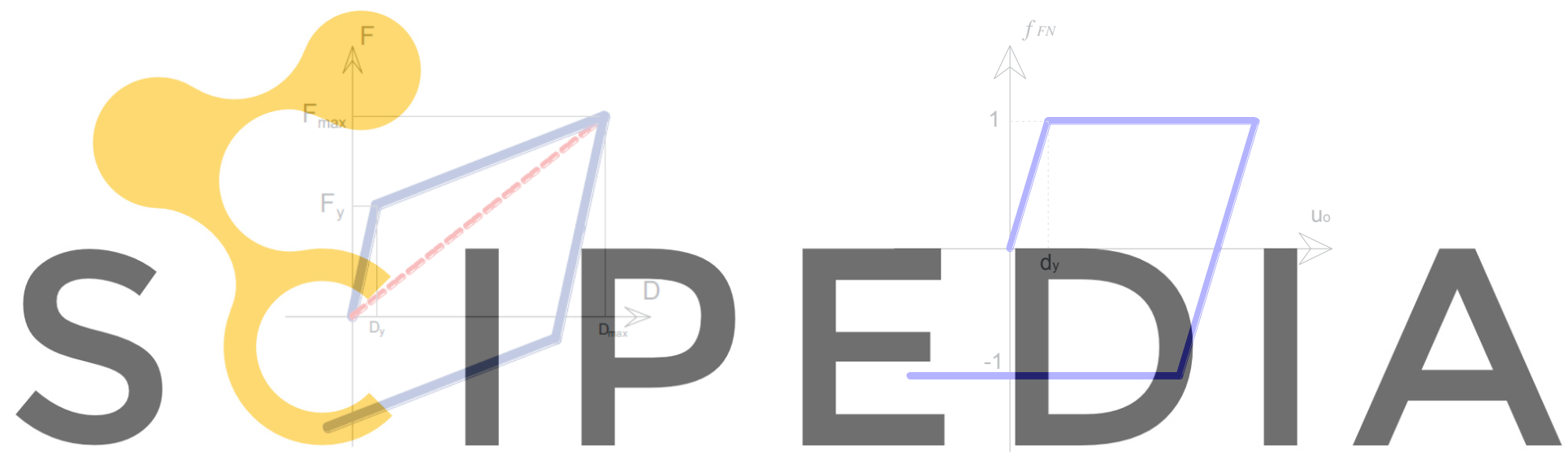

Figure 4: Hysteretic rules for fead Rubber Bearings (left) and Flat Sliders (right) devices.
Register for free at https//WWW.scipedia.com to download the version without the watermark

In order to consider the actual variability of the main mechanical properties, variability scale

factors have been adopted: such scale factors for each analysis are returned by numerical simulators which follow the probability density functions reported in Figure 2 and Figure 3, and represent the ratios between the real mechanical property and the design value. if a large number of simulations is adopted for each analyzed seismic input, a significantly robust set of data can be obtained, and reasonable statistical analyses can be performed. In the results sections, the variability of the main response parameters has been evaluated, for the mean value of each quantity, within a set of spectrum-compatible seismic events. For each record, 10 '000 simulations have been performed, and for each set analysis mechanical properties are scaled by different scale factors, in order to consider the most general cases.

\section{SEISMIC INPUT}

According to the Italian Building Code 2018 [4], a spectrum-compatible set of ground acceleration time series have been analyzed, in order to study the consequent variability of the mean response, by assuming mechanical properties as random variables, instead of a 
deterministic quantities. Natural records have been adopted, and scaled, in order to obtain better agreement of the single event response spectrum with respect to the target one, provided by the code. precisely, the following seismic hazard parameters have been assumed:

- Construction site: L’Aquila

- Soil class: C;

- Topographic category: T1;

- Limit state: Collapse Limit State (return period: 975 years).

Records have been selected through the software REXEL [7], which allows to obtain spectrum-compatible set of seismic events, according to several standard codes. Thus, scale factors bounded between 0.5 and 2 have been considered, in order not to obtain unrealistic ground motion time series, in terms of frequency and amplitude. The mean spectrum has been bounded between $90 \%$ and $130 \%$ of the target one, as ruled by the standard code, in a period range between $0.15 \mathrm{sec}$ and $120 \%$ of the isolation period (upper bound: $3.6 \mathrm{sec}$ ). In Figure 5 results of the spectrum-compatibility study are reported.
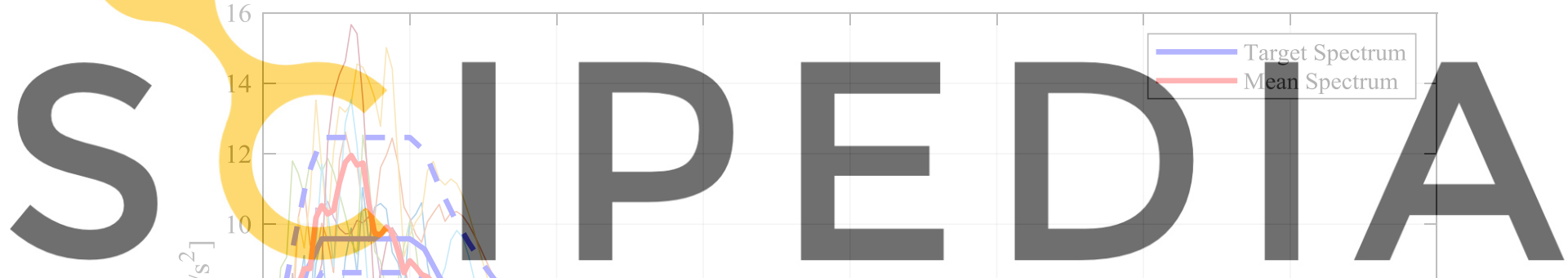

Register for free at https/NWww.scipedia.com to download the version without the watermark

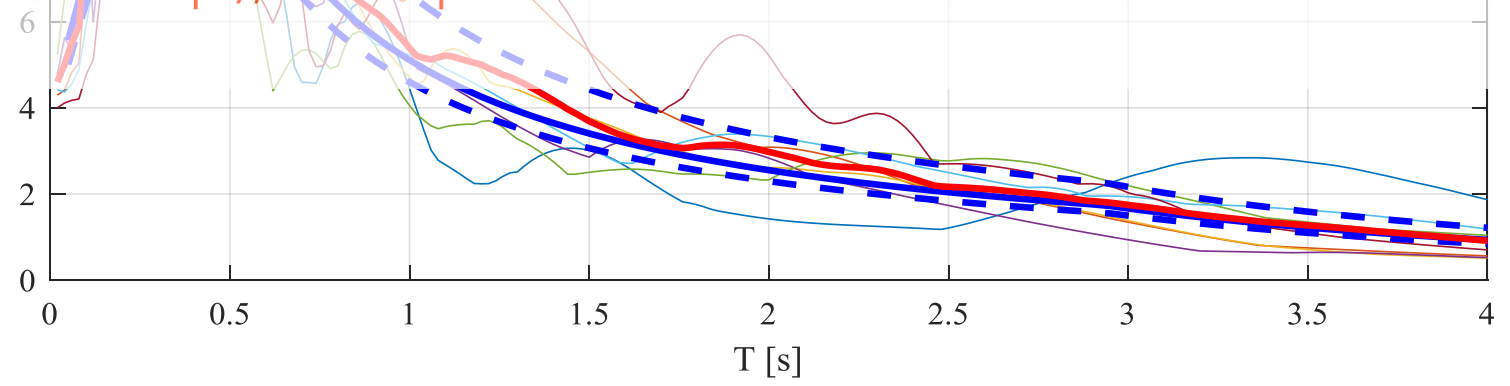

Figure 5: Spectrum-compatibility graphical results.

In Table 1 the selection of the adopted records is listed. 
Marco Furinghetti and Alberto Pavese

\begin{tabular}{cccccccc}
\hline Event \# & Earthquake Name & Date & Mw & $\begin{array}{c}\text { Epicentral } \\
\text { Distance }(\mathbf{k m})\end{array}$ & $\begin{array}{c}\text { Original } \\
\text { PGA [g] }\end{array}$ & $\begin{array}{c}\text { Scaled } \\
\text { PGA [g] }\end{array}$ & $\begin{array}{c}\text { Scale } \\
\text { factor [\#] }\end{array}$ \\
\hline 1 & Kalamata & $13 / 09 / 1986$ & 5.9 & 10.0 & 0.215 & 0.429 & 2.00 \\
\hline 2 & Kalamata & $13 / 09 / 1986$ & 5.9 & 11.0 & 0.240 & 0.479 & 2.00 \\
\hline 3 & Dinar & $01 / 10 / 1995$ & 6.4 & 8.0 & 0.319 & 0.404 & 1.27 \\
\hline 4 & Izmit & $17 / 08 / 1999$ & 7.6 & 47.0 & 0.238 & 0.475 & 2.00 \\
\hline 5 & Imperial Valley & $15 / 10 / 1979$ & 6.5 & 27.0 & 0.485 & 0.485 & 1.00 \\
\hline 6 & Imperial Valley & $15 / 10 / 1979$ & 6.5 & 27.7 & 0.519 & 0.519 & 1.00 \\
\hline 7 & Erzincan & $13 / 03 / 1992$ & 6.6 & 9.0 & 0.495 & 0.446 & 0.90 \\
\hline
\end{tabular}

Table 1: Selection of adopted natural records.

With a selection of at least 7 records, the Italian Building Code allows to consider the mean response as reference quantities in order to check the structural behavior of the designed system.

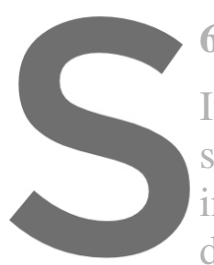

\section{RESULTS}

In this section result

system. Firstly, refere

integration of the dynat
design value of mechan

have been considered as distributions of mean response parameters, by considering 10'000

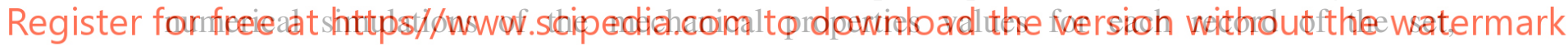
according to the assumed probability density functions. Results have been normalized with respect to the correspondent value of the reference case, so that the actual variability about the mean value can be directly evaluated. Special attention has been focused on displacement, interstorey drift, isolation and base shear forces responses.

\subsection{Reference case}

The reference case has been initially studied, by considering the adopted spectrum-compatible set, and the design value of the mechanical properties of isolation devices. In Figure 6 and Figure 7 displacement and interstorey drift responses are reported for each level of the structural system, whereas in Figure 8 the force response of both the isolation system and the building base are provided. 

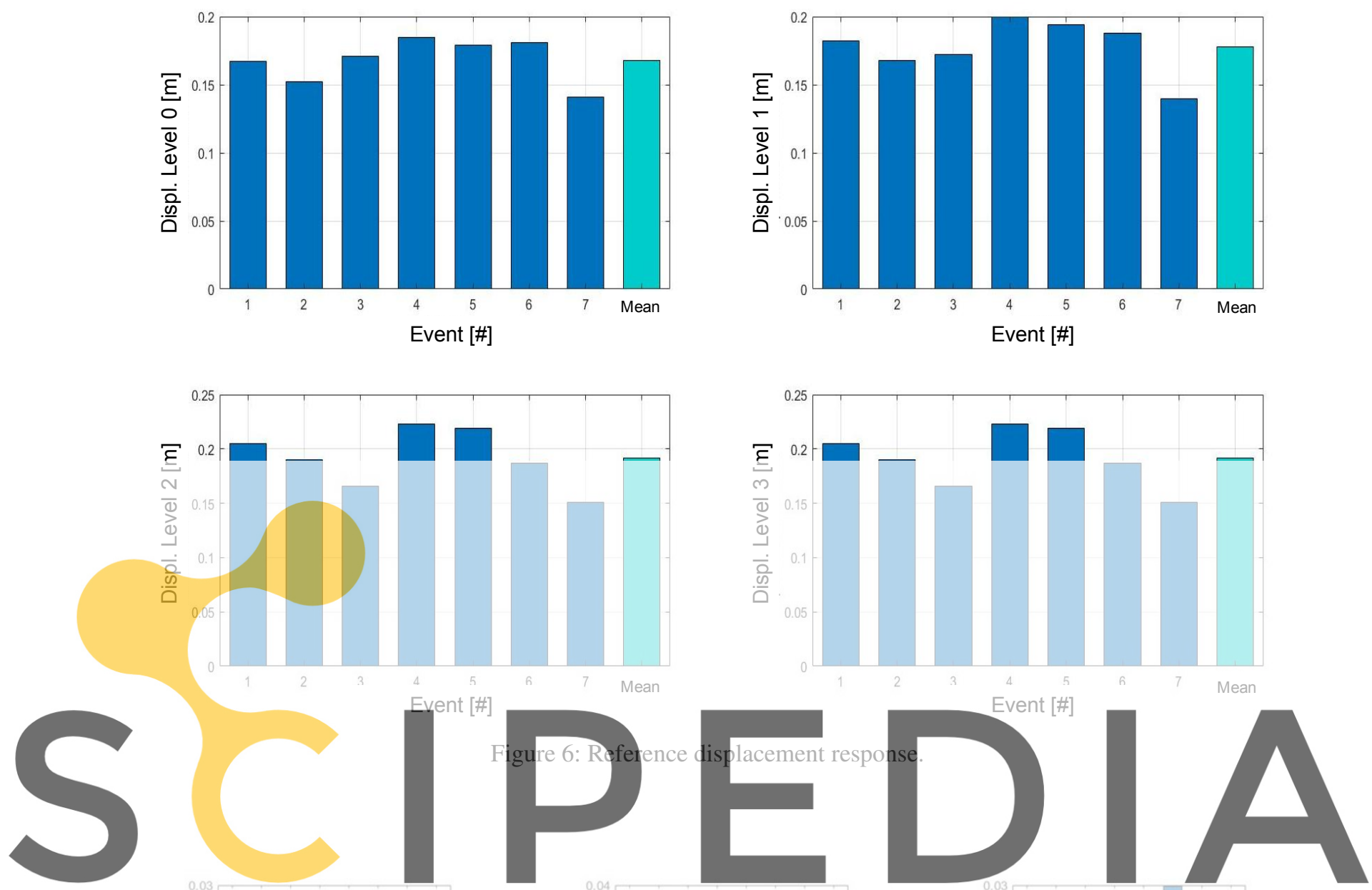

Register for free at https//www.scipedia.com to download the version without the watermark
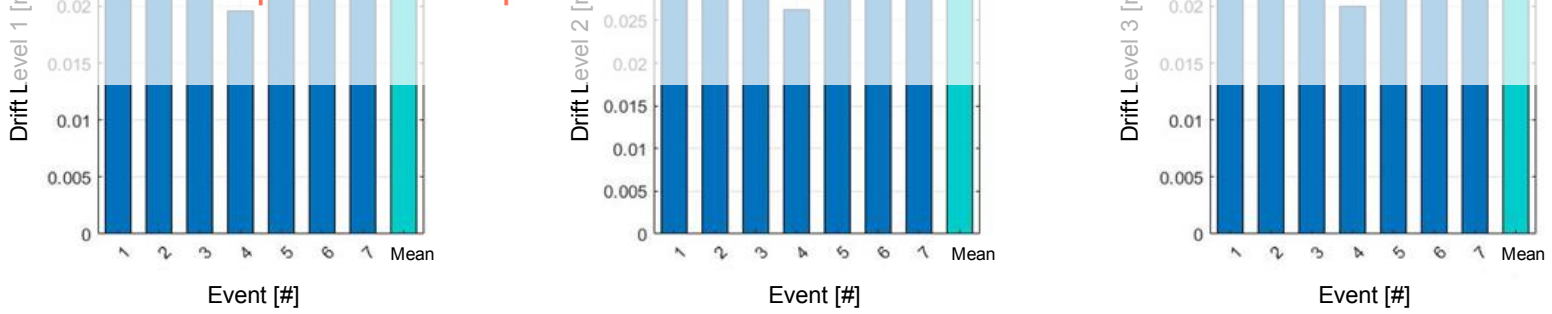

Figure 7: Reference interstorey drift response.

The variability of the single-event quantity with respect to the mean value is very limited, due to the high level of spectrum-compatibility of the selected records, and consequently comparable loading conditions are ensured among the applied seismic events, especially concerning the drift response at all levels. 

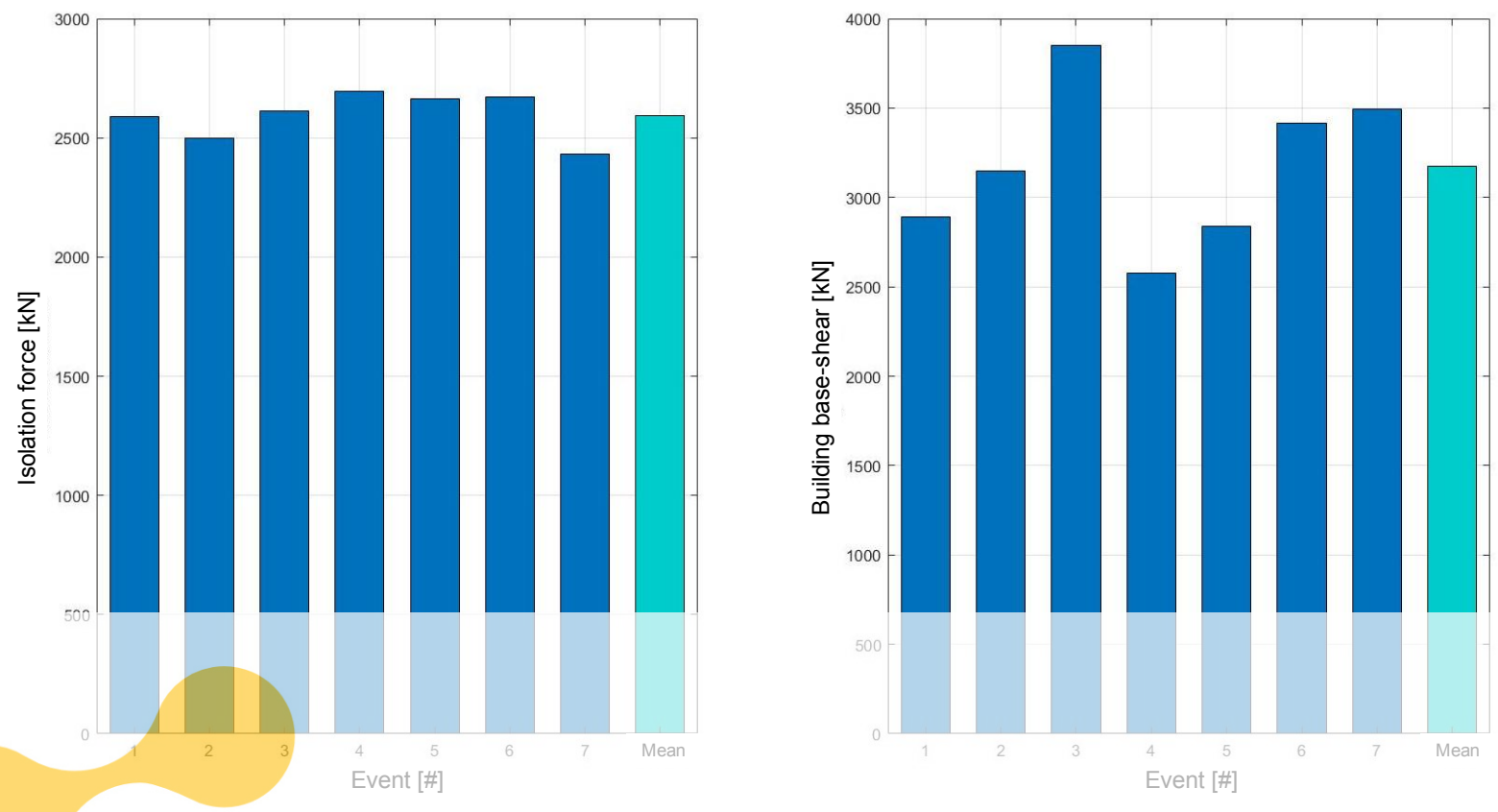

Figure 8: Reference isolation and building force responses.

Both the isolation system and the building base force response variation about the mean reference case looks even lower, in compar son to displacement variability. The building average base shear is significantly lower of the strength of the buinding (Figure 1), and consequently the linear elastic response of the superstructure is ensured.

6.2 Evaluation of the most influencing parameter

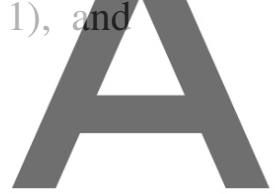

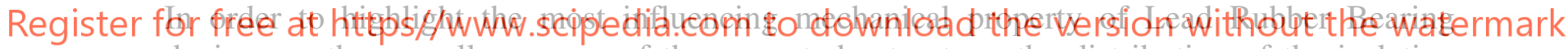
devices on the overall response of the case study structure, the distribution of the isolation displacement has been considered, by assuming individually mechanical properties as randome variable, namely the shear modulus $G$ of rubber portion and the yielding strain and stress of the lead core. In Figure 9 results are shown.
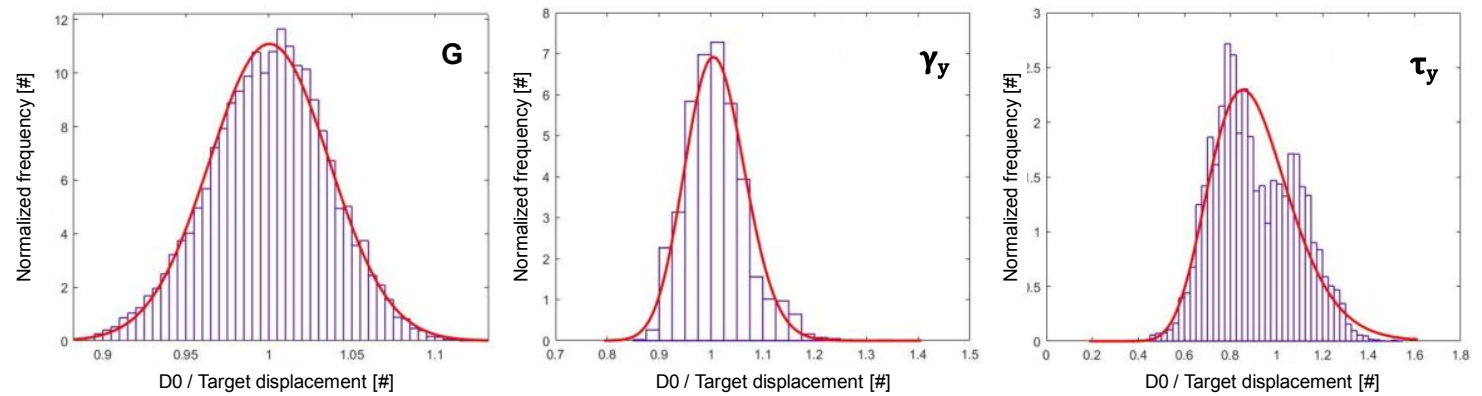

Figure 9: Distribution of the isolation displacement induced by rubber shear modulus (left) and the lead yielding strain (centre) and stress (right). 
As can be noted the highest contribution in the isolation displacement response variability is provided by assuming the yielding stress of the lead core as a random variable, with a consequent standard deviation in the isolation displacement of $30 \%$. Thus, in the next analyses the rubber shear modulus and the lead core yielding strain have been adopted as deterministic values, and the lead core yielding stress has been implemented as randomly extracted by a numerical simulator, which follows the aforementioned distribution.

\subsection{Mean displacement and drift response}

In Figure 10 and Figure 11 results related to the displacement response of the strucure are provided, in terms of both displacement and drifts values. Precisely, the distribution of the mean value among the selected seismic events is studied, since the mean response is the reference value for an input set with at least 7 events.
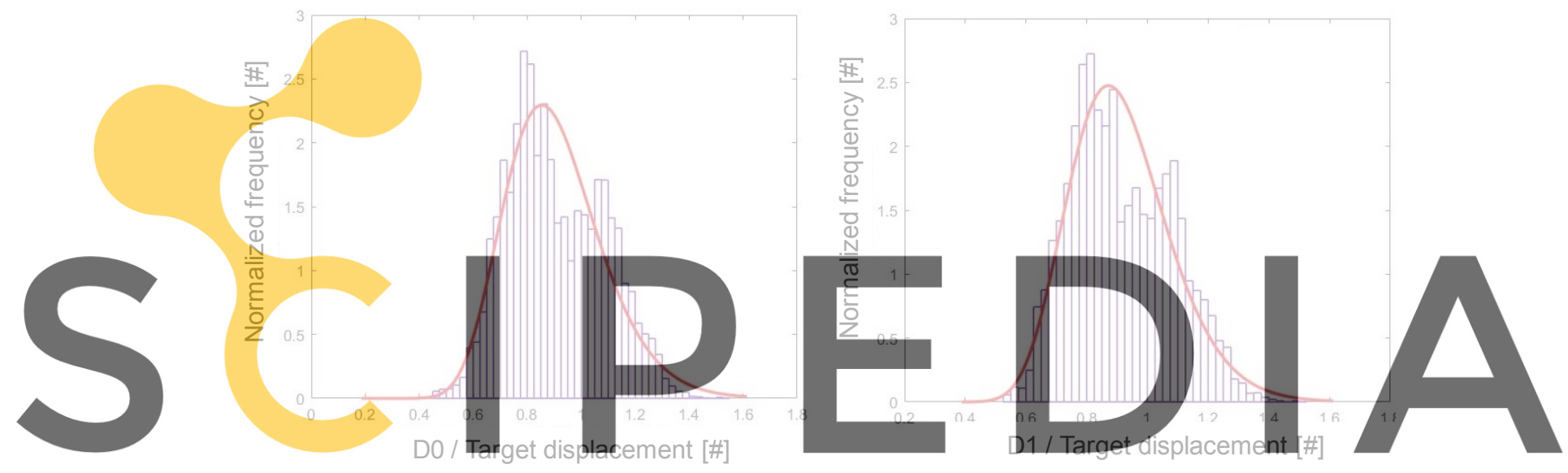

Register for free at https//www.scipedia.com to download the version without the watermark
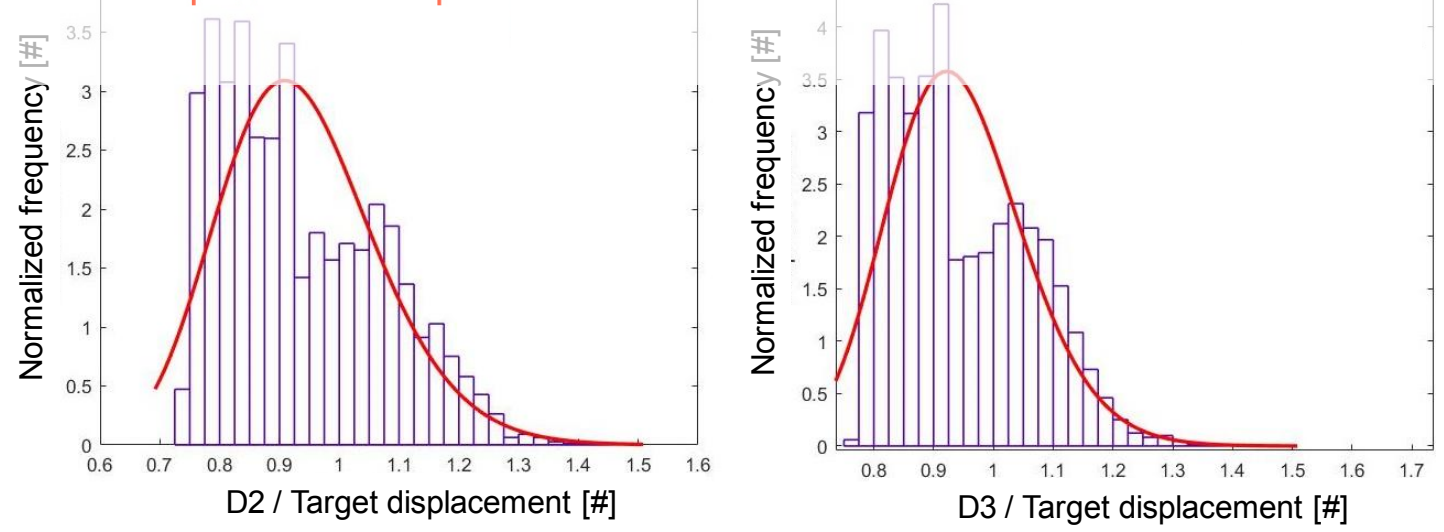

Figure 10: Mean displacement response. 

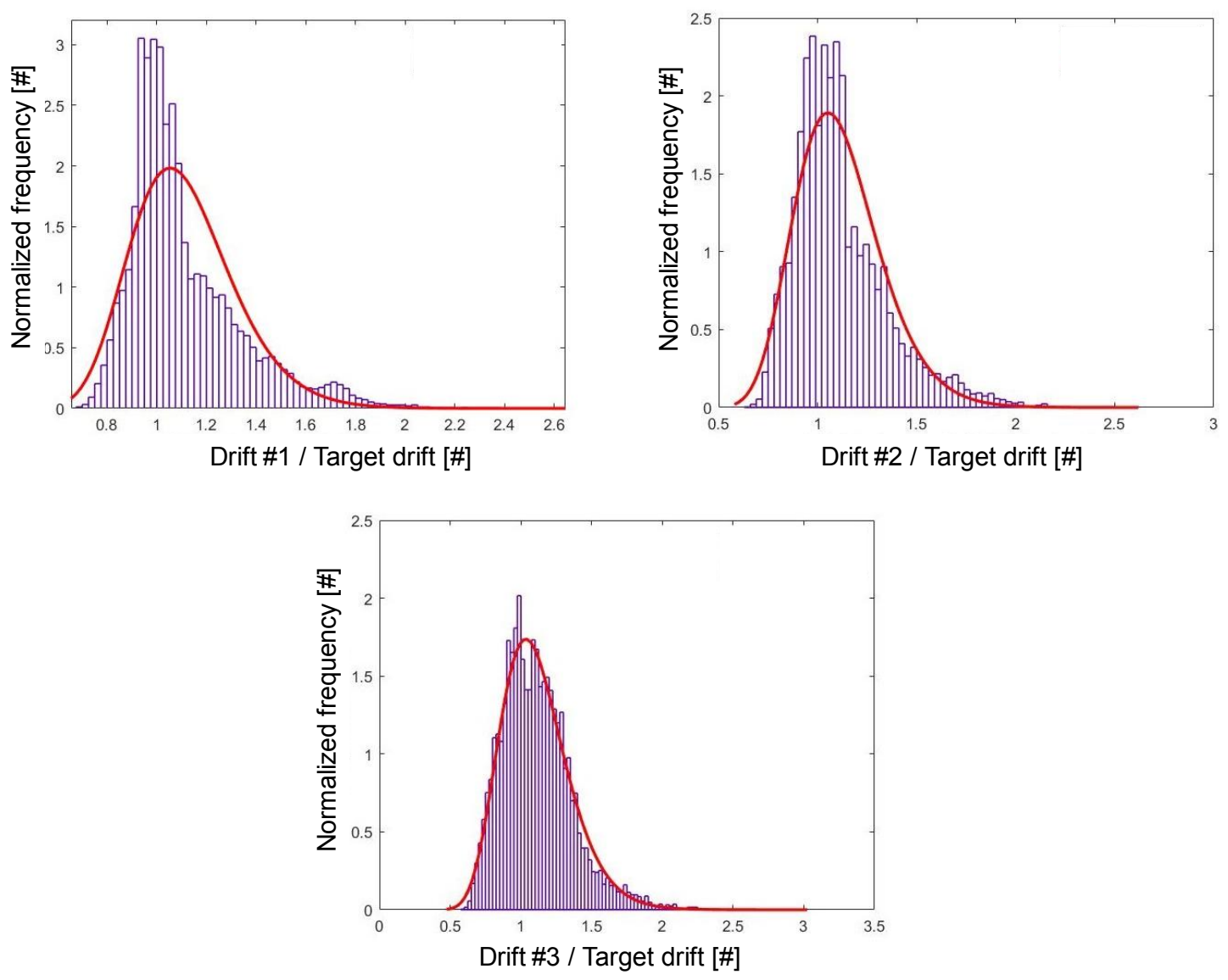

Figure 11: Mean drift response.

Results show that the displacement response variability can be represented by a standard deviation value approximately equal to $30 \%$ for the isolation level, and seems to slightly decrees as higher floors are considered. An opposite behavior can be noticed for the drift response, where a higher variability can be noticed, as higher levels of the structure are analyzed. Precisely, starting from $20 \%$ standard deviation at the ground floor of the building, variability values close to $40 \%$ can be detected for the last floor of the case study structure.

\subsection{Mean Isolation system \& Building Force responses}

In Figure 12 results related to the force response of both the isolation system and the building base shear are reported.

As expected the variability induced by the random yielding stress of the lead core in the force response is lower than the observed values of the displacement response, and standard deviations close to $20 \%$ can be computed. 

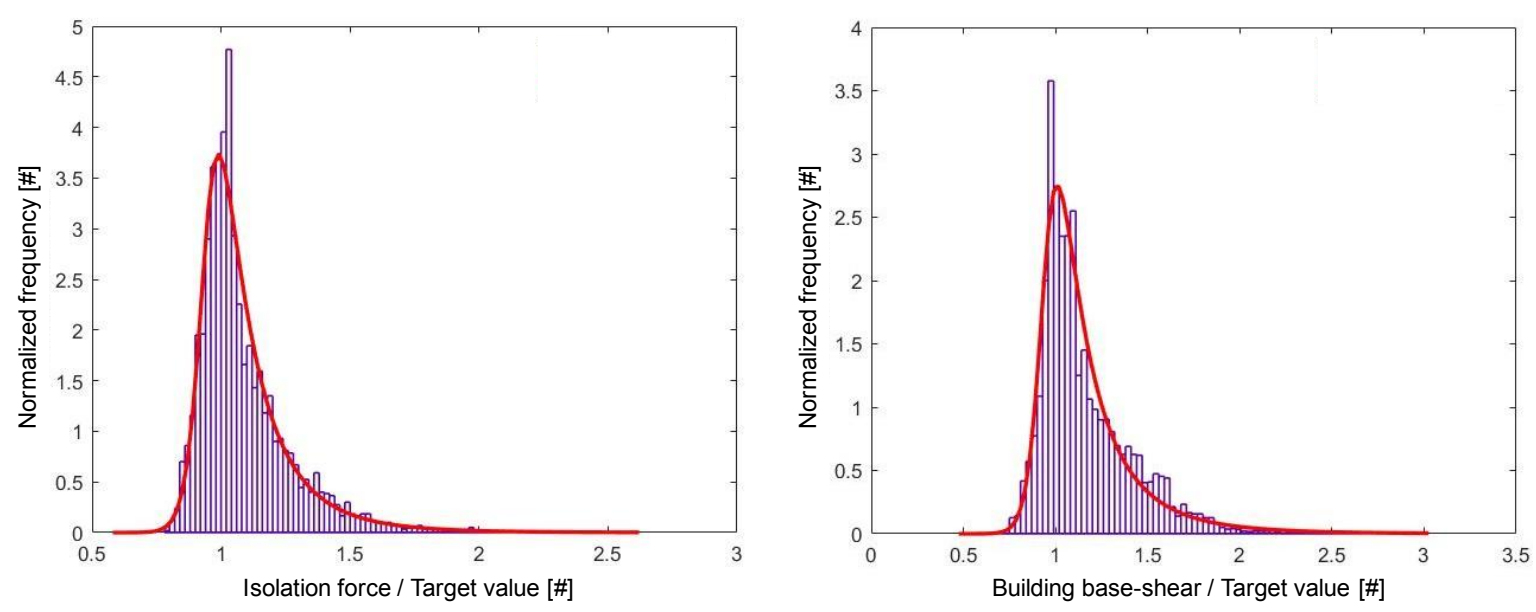

Figure 12: Mean isolation system and building force responses.

Nonetheless, such variability should be accounted for in both design and assessment procedures of base-isolated building, in order to better estimated the proper displacement and force demands.

\section{CONCLUSIONS AND FUTURE DEVELOPMENTS}

In the present endeavor the seismic response of a base-isolated building has been assessed through Non-Linear Time History Analyses, by adopting a set of natural scaled records, spectrum-compatible to the target spectrum provided by the Italian Building Code or the construction site. More specifically, the isolation layer consists of a combination of Lead Rubber Bearings and Flat Slider, with a design effective period of $3.0 \mathrm{sec}$ and an equivalent viscous damping of $30 \%$. Mechanical properties have been considered as random variables, according to a statistical study carried out on a wide set of dynamic tests performed at the Laboratory of EUCENTRE Foundation of Pavia (Italy). Results have highlighted the folloing standpoints:

- The most influencing mechanical property is represented by the yielding stress of the lead core, which is the parameter directly associated to the force response of LRB devices and related to a high value of standard deviation;

- The variability effect of the rubber shear modulus and the lead core yielding strain can be fairly neglected, and then such parameters can be considered as deterministic values for both design and assessment procedures;

- By accounting for the effective experimental variability of the yielding shear stress of the led core for LRB devices, the displacement response is characterized by nonnegligible value of standard deviations (starting from averagely 25\% the isolation level) and such variability decreases and increases respectively for displacement and drift responses;

- Concerning the force response, lower variability can be computed for both the isolation layer and the building base shear, even though standard deviation values can not be neglected (around 20\%). 
This research topic needs to be further investigated, by considering additional procedure for the mean response computation, and additional case study structures have to be analyzed, in order to generalize the drawn conclusions.

\section{ACKNOWLEDGMENTS}

Part of the current work has been carried out within the national Research Project DPC ReLUIS (National Network of Laboratories of Seismic Engineering), WP15, Contributions to Standard Codes for Seismic Isolation and Energy Dissipation.

\section{REFERENCES}

[1] Chopra AK, Dynamics of Structures Theory and Applications to Earthquake Engineering. Prentice Hall, Upper Saddle River, NJ, 1995.

[2] AASHTO (2014) Guide Specifications for Seismic Isolation Design, American Association of State Highway and Transportation Officials, Washington, DC.

[3] CEN (2009) Comité Européen de Normalisation TC 340, European Code UNI EN 15129:2009 Anti-seismic devices, European Committee for Standardization, Brussels, Belgium.

[4] D.M. 17/01/2018 - Norme Tecniche per le Costruzioni, D.M. 17/01/2018, Gazzetta Ufficiale 20/02/2018, Italia.

[5] Dolce M, Cardone D, Croatto F (2005) Frictional behavior of steel-PTFE interfaces for seismic isolation. Bulletin of Earthquake Engineering, 3, 75-99.

[6] Furinghetti M., Lanese I., Pavese A. (2020), Experimental assessment of the seismic response of a base isolated building through hybrid simulation technique. Frontiers in Built Environment, DOI: 10.3389/fbuil.2020.00033.

[7] Iervolino I, Galasso C, Cosenza E (2009), REXEL: computer aided record selection for code-based seismic structural analysis. Bulletin of Earthquake Engineering, DOI: 10.1007/s10518-009-9146-1.

[8] Lee D., Constantinou M.C. (2016), Further results on the heating of single and multicore lead-rubber bearings and dampers. Bull Earthquake Eng, DOI 10.1007/s10518015-9830-2.

[9] Peloso S., Pavese A., Casarotti C. (2012). Eucentre trees lab: Laboratory for training and research in earthquake engineering and seismology. Geotechnical, Geological and Earthquake Engineering, Vol. 20, pp. 65-81.

[10] Seismosoft. SeismoStruct 2016 - A computer program for static and dynamic nonlinear analysis of framed structures. 2016, available from http://www.seismosoft.com. 